\title{
INCLUSÃO DIGITAL NAS ESCOLAS PÚBLICAS DE CONSELHEIRO LAFAIETE
}

\author{
Diego Costa Lima ${ }^{1}$, Pamella Renata F. D. Ladeira ${ }^{2}$, Natã Goulart da \\ Silva ${ }^{3}$, Fernando Augusto Teixeira ${ }^{4}$
}

Resumo: O propósito desse trabalho é demonstrar o funcionamento de um projeto de inclusão digital que foi realizado em escolas públicas da cidade de Conselheiro Lafaiete - MG. Este projeto é fruto de uma pareceria entre a Universidade Federal de São João del-Rei, a prefeitura da cidade de Conselheiro Lafaiete - MG e a regional da Secretaria estadual de educação. Neste projeto foram envolvidos alunos da universidade que atuaram como bolsistas e voluntários e de professores que coordenavam o projeto. Várias escolas públicas dispõem de computadores e acesso à internet, todavia não contam com pessoas qualificadas para dar suporte ao ingresso dos alunos e da comunidade escolar à inclusão digital. Tendo em vista esse problema, foi iniciado em 2010 na cidade de Conselheiro Lafaiete - MG um projeto visando que os alunos das escolas municipais tenham acesso à capacitação básica a computadores e a Internet.

Palavras-chave: Inclusão digital. Laboratórios de informática. Mundo digital.

DIGITAL INCLUSION IN THE PUBLIC SCHOOLS OF COUNCILOR LAFAIETE

Abstract: The purpose of this work is to demonstrate the operation of a digital inclusion project that was carried out in public schools in the city of Conselheiro

1 Universidade Federal de São João Del Rei (UFSJ) - Campus Alto Paraopeba. Discente do Curso de Engenharia Mecatrônica da UFSJ - Campus Alto Paraopeba. E-mail: diegocostalima94@hotmail. com.

2 Universidade Federal de São João Del Rei (UFSJ) - Campus Alto Paraopeba. Discente do Curso de Engenharia Química da UFSJ - Campus Alto Paraopeba. E-mail: pamellaladeiraoo@gmail.com.

3 Universidade Federal de São João Del Rei (UFSJ) - Campus Alto Paraopeba. Docente na UFSJ Campus Alto Paraopeba. E-mail: teixeiracl@gmail.com.

4 Universidade Federal de São João Del Rei (UFSJ) - Campus Alto Paraopeba. Docente na UFSJ Campus Alto Paraopeba. E-mail: ngoularts@gmail.com 
Lafaiete - MG. This project is the result of an agreement between the Federal University of São João del-Rei, the city council of the city of Conselheiro Lafaiete MG and the regional of the State Secretariat of Education. In this project students of the university were involved who acted as fellows and volunteers and of teachers who coordinated the project. Several public schools have computers and Internet access, but they do not have qualified people to support the entry of students and the school community into digital inclusion. In view of this problem, a project was initiated in 2010 in the city of Conselheiro Lafaiete - MG, aiming at the students of the municipal schools to have access to the basic training for computers and the Internet.

Keywords: Digital inclusion. Computer laboratories. Digital world.

INCLUSIÓN DIGITAL EN LAS ESCUELAS PÚBLICAS DE CONSEJERO

\section{LAFAIETE}

Resumen: El propósito de este trabajo es demostrar el funcionamiento de un proyecto de inclusión digital que fue realizado en escuelas públicas de la ciudad de Conselheiro Lafaiete - MG. Este proyecto es fruto de una opinión entre la Universidad Federal de São João del Rey, la alcaldía de la ciudad de Conselheiro Lafaiete - MG y la regional de la Secretaría estadual de educación. En este proyecto participaron alumnos de la universidad que actuaron como becarios y voluntarios y de profesores que coordinaban el proyecto. Varias escuelas públicas disponen de ordenadores y acceso a Internet, pero no cuentan con personas calificadas para dar soporte al ingreso de los alumnos y de la comunidad escolar a la inclusión digital. En vista de este problema, se inició en 2010 en la ciudad de Conselheiro Lafaiete - MG un proyecto para que los alumnos de las escuelas municipales tengan acceso a la capacitación básica a computadoras e Internet.

Palabras clave: Inclusión digital. Laboratorios de informática. Mundo digital.

\section{INTRODUÇÃO}

Ao longo dos anos observamos algumas iniciativas governamentais realizadas com o objetivo de promover a inclusão digital de alunos nas escolas públicas, como pode ser observado no portal Governo Eletrônico ${ }^{[1]}$. Dentre estas iniciativas verifica-se de maneira prática a compra e envio de computadores e estrutura de redes para montagem de laboratórios de informática nas escolas. Porém, em muitas escolas faltam pessoas capacitadas para administrar os laboratórios de informática, realizando a manutenção dos equipamentos ou 
ministrando os treinamentos. Esta carência leva a não utilização dos recursos, dificultando assim o acesso dos alunos de baixa renda às Tecnologias de Informação e Comunicação (TIC).

Para suprir a demanda da administração de recursos e capacitação de professores e alunos nas escolas públicas da região do Alto Paraopeba, foi criado o projeto de extensão Inclusão Digital nas Escolas Públicas de Conselheiro Lafaiete. Este projeto de extensão permite que alunos dos cursos de engenharia da Universidade Federal de São João del-Rei possam atuar em parceria com as escolas da região no desenvolvimento de atividades de inclusão digital.

A cidade de Conselheiro Lafaiete - MG possui 127.369 habitantes segundo o IBGE ${ }^{[2]}$, sendo as escolas públicas responsáveis pela formação no ensino básico e médio da maioria das crianças e adolescentes da cidade. Muitas escolas possuem laboratórios de informáticas, mas a falta de pessoas capacitadas leva a subutilização dos recursos e a não utilização do potencial inclusivo dos mesmos.

De acordo com o mapa da inclusão digital da Fundação Getúlio Vargas (FGV), que realizou um ranking de acesso domiciliar em 2010 contando com 5565 municípios. Temos que Conselheiro Lafaiete aparece na $227^{\mathrm{a}}$ posição no Brasil, com cerca de 53,31\% dos domicílios com microcomputadores e na $265^{\mathrm{a}}$ posição no Brasil, com cerca de $41,64 \%$ dos domicílios que possuem microcomputadores com internet. A cidade de Conselheiro Lafaiete - MG encontra-se abaixo até mesmo de seus vizinhos na região do Alto Paraopeba, como Ouro Branco - MG, que encontra-se na $85^{\text {a }}$ posição no Brasil, com cerca de $58,68 \%$ dos domicílios que possuem microcomputadores, e na $82^{\text {a }}$ posição no Brasil, com cerca de 47,98\% dos domicílios que possuem microcomputadores com internet. ${ }^{[3]}$

Este programa de inclusão digital é uma continuidade e expansão de um projeto de extensão iniciado no ano de 2010. Ao longo dos anos, o projeto inicial atendeu escolas, realizando a administração dos laboratórios de informática, tornando-os disponíveis para o uso de alunos e professores desde então. Foram feitos treinamentos de 12 horas para pequenas turmas com emissão de certificados para os alunos concluintes. Esta experiência e os resultados obtidos no projeto foram publicados no V Congresso Brasileiro de Extensão Universitária, CBEU. ${ }^{[4]}$

Dentre as principais atividades desenvolvidas na área de inclusão digital por projetos de extensão da UFSJ podemos destacar a execução no ano de 2015 de um projeto de infraestrutura de redes que tinha como objetivo deixar em 
condições de operação os laboratórios de 16 escolas públicas estaduais dentro do município de Conselheiro Lafaiete - MG. As escolas atendidas foram:

- Escola Estadual Domingos Bebiano;

- Escola Estadual Dr. Antero Chaves;

- Escola Estadual Dr. Ant. Nogueira de Rezende;

- Escola Estadual Gen. Sylvio Raulino de Oliveira;

- Escola Estadual Geraldo Bittencourt;

- Escola Estadual Isaura Ferreira;

- Escola Estadual Lopes Franco;

- Escola Estadual Luiz de Mello Vianna Sobrinho;

- Escola Estadual Moacir de Souza Dias;

- Escola Estadual Mons. Antônio José Ferreira;

- Escola Estadual Monsenhor Horta;

- Escola Estadual Narciso de Queirós;

- Escola Estadual Pacífico Vieira;

- Escola Estadual Professor Astor Vianna;

- Escola Estadual Professora Maria Augusta Noronha;

- CESEC Prof. José Martins Sobrinho.

Após a adequação dos laboratórios, no ano de 2016, o número de escolas atendidas pelo projeto foi ampliado. Neste ano foram ministrados em cada escola cursos com duração de um mês, para que assim fosse possível atingir todo o público interessado.

No ano de 2017 houve uma redução do número de escolas atendidas e um aumento da carga horária dos cursos, isso deve-se ao fato do projeto ter dado um enfoque maior na estruturação do mesmo, para que houvesse uma melhor base para atender os alunos, e também para evitar perdas de conhecimento entre as trocas de pessoas que estavam saindo e entrando no projeto.

$\mathrm{O}$ projeto descrito nesse trabalho, almeja ajudar a comunidade escolar a adquirir conhecimentos básicos de informática, a fim de facilitar as tarefas escolares e difundir o conhecimento digital. Além disso, apresenta noções de 
programação de computadores para crianças e jovens, despertando o interesse e aumentando o raciocínio lógico com o auxílio de programas como o Scratch. ${ }^{[5]}$

O Scratch é um programa de computador que foi projetado especialmente para crianças e jovens com idades entre 8 e 16 anos, mas pode ser usado por pessoas de todas as idades. Ele também é muito usado nas instituições escolares, de diversos níveis (desde a escola primária à universidade), em variadas disciplinas (como Matemática, Biologia, História, Idiomas, entre outros). Com isso, a iniciativa Scratch Brasil fornece um espaço de uso gratuito para os educadores, aplicarem seu uso na sala de aula, disponibilizando fóruns, tutoriais, jogos, videoaulas, entre outros recursos que são aproveitados e implantados no projeto. ${ }^{[5]}$

Na Figura 1 é apresentado um exemplo de atividade com conceitos básicos de matemática desenvolvida com os alunos sobre o conteúdo de iniciação a programação de computadores aplicado a complementação do ensino tradicional.

FIGURA 1: Jogo de adições.

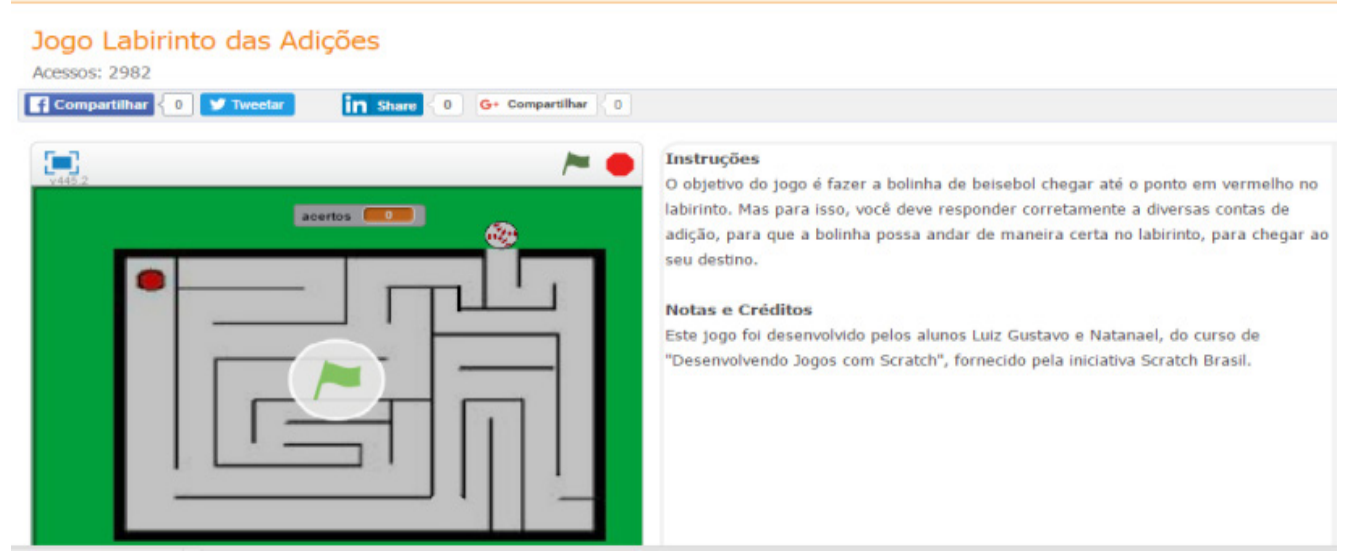

FONTE-SCRATCH BRASIL

Dessa forma, a universidade auxilia no processo de inclusão digital das comunidades, atuando principalmente em escolas inseridas em regiões carentes. Baseado nos dados de exclusão digital, verifica-se que o país necessita de projetos que mudem esse panorama. Por outro lado, estes projetos propiciam aos discentes das universidades experiências profissionais que complementam sua formação curricular. 


\section{Material e Metodologia}

Este programa de inclusão digital é uma continuidade e uma expansão de um projeto de extensão iniciado no ano de 2010. O projeto contemplou muitas escolas, realizando a administração dos laboratórios de informática, colocando-os em pleno funcionamento e garantindo a disponibilidade para o uso de alunos e professores desde então.

Em todos os anos de andamento do projeto, os resultados foram gratificantes para a comunidade escolar e uma experiência muito enriquecedora para os bolsistas e para os professores envolvidos no projeto. Com base nas experiências iniciais, o programa foi ampliando sua atuação.

O programa atualmente conta com um aluno bolsista, um aluno voluntário e dois professores (um coordenador e um orientador). A execução do projeto consiste em atividades com total de 20 horas semanais de participação do bolsista e do voluntário. A execução ocorre com uma parceria com a SRE - Superintendência Regional de Ensino, com a emissão de uma declaração atestando que o bolsista ou voluntário está participando do projeto, e que os mesmos tenham autorização para executarem as atividades em qualquer escola que aceite os treinamentos. Além disso, continua sendo prioridade no programa, alunos que não têm acesso à internet ou que possuem acesso restrito.

O bolsista e voluntário envolvido no projeto atuam ministrando os treinamentos, e as pessoas contempladas no programa desenvolvem as atividades apoiadas no material didático desenvolvido pelos universitários bolsistas ou voluntários sob a orientação dos docentes. Seguem abaixo os temas que são abordados no programa:

- Introdução: Regras básicas de comportamento em um laboratório, como a informática começou, conceitos básicos, conceitos de hardware e software, partes internas de um computador;

- Ambiente operacional: Noções gerais sobre o sistema operacional, sistema operacional Linux Educacional, desligando e reiniciando o computador, janelas, análise de cada componente de uma janela, abrir uma pasta, criar uma pasta, abrir arquivos, renomear arquivos, copiar arquivos, mover arquivos, deletar arquivos, descompactar arquivos ou pastas, lixeira: restaurar arquivos e pastas, deletar arquivos, esvaziar a lixeira, procurar 
arquivos ou pasta, programas básicos (antivírus, calculadora, bloco de notas), utilização de portas USB (pen drives, celulares);

- Editores de texto: Criação de um novo documento de texto, salvar o documento de texto, abrir um texto, digitação de um texto, formatação básica do texto: formatação padrão, caractere, parágrafo, marcadores e numerações, alterar caixa, inserindo: figura, número de página, caractere especial, cabeçalho, rodapé, operações sobre tabelas: inserir tabela, inserir linha, inserir coluna, excluir tabela, excluir linha, excluir coluna, selecionar tabela, selecionar linha, selecionar coluna, mesclar células, dividir células, dividir tabelas, auto formatar, auto ajustar, formato numérico, fórmula, usando algumas ferramentas: ortografia, contagem de palavras, edição de fórmulas matemáticas, edição de fórmulas matemáticas, inserindo: sumário, exportando: exportando para PDF;

- Editores de apresentação: Introdução, assistente de apresentação, tipo de apresentação, conhecendo o Impress: criando a primeira apresentação com o Impress, formatando sua apresentação: formatação de caractere, salvando slides, assistindo a uma apresentação, inserindo objetos: abrir uma apresentação existente, inserir slide, duplicar slide, inserir imagem, mover slides, inserir som, adicionar som para toda a apresentação de slide, inserir hiperlink na apresentação de slide, slide mestre, criando um slide mestre, estrutura da apresentação: efeito de transição, personalizando a apresentação: apresentação cronometrada;

- Planilha eletrônica: Introdução ao software de planilhas eletrônicas: conceitos básicos, iniciando o BrOffice Calc, formatando células, inserindo fórmulas, assistente de funções, gráficos, inserir: quebra de página, quebra de coluna, anotação, proteger documento, formatação condicional;

- Internet: Pesquisas, e-mail, transferências de arquivos e segurança na internet;

- Noções de programação: Conhecimentos da lógica de programação atrelada a efeitos visuais através do programa Scratch.

O projeto conta com a utilização de apostilas desenvolvidas e disponibilizadas na forma digital. As práticas são integradas, ou seja, o aluno faz uma 
atividade explorando todos os recursos digitais propostos. Os temas das práticas são sobre situações cotidianas da vida dos alunos para que o aprendizado seja de fácil aplicação na vida da comunidade. Além disso, o projeto aproxima a comunidade da Universidade que agora surge como uma parceira em seu desenvolvimento. ${ }^{[6]}$

No ano de 2017 ocorreram alterações na forma de aplicação do projeto nas escolas. Observou-se que o projeto atendia um grande número de crianças, mas com a aplicação de conteúdos superficiais. Verificou-se também que as apostilas se encontravam desatualizadas, ocasionando uma maior dificuldade em lecionar as aulas, pois informações e comandos indicados na apostila estavam em lugares diferentes nos softwares. Os arquivos não estavam organizados nos serviços de armazenamentos na nuvem, dificultando assim a procura e com problemas de transição quando ocorria a troca dos alunos envolvidos no projeto, fazendo com que muitas vezes algumas atividades tinham que ser reiniciadas, como a geração de novas apostilas. Com base nessa análise foi definido que seriam selecionados pequenos números de turmas de alunos para que assim o bolsista tivesse tempo para a organização e documentação das atividades e dos materiais didáticos utilizados nos cursos.

O processo iniciou-se com a organização de todas as pastas e arquivos presentes no repositório de dados, colocando anos dos projetos realizados, e também renomeando arquivos, tudo isso para reduzir o tempo de busca de determinado arquivo, e também para que o próximo bolsista ou voluntário a atuar no projeto pudesse observar a evolução e também trabalhar com o que há de mais atualizado, evitando assim o risco da utilização de um arquivo que não foi atualizado. Desta forma os materiais didáticos foram classificados de acordo com a versão dos programas utilizados.

Depois da organização dos arquivos, foi realizado uma busca pelos programas de computador utilizados no projeto como: pacote LibreOffice, Scratch, Máquinas Virtuais, Linux Educacionais. Essa busca por endereços de downloads dos programas tem como função principal, orientar o próximo bolsista ou voluntário atuante no projeto a não perder tempo procurando quais devem ser os programas ou softwares utilizados.

A etapa seguinte foi a criação de alguns formulários eletrônicos através da plataforma disponibilizada pelo Google para acompanhamento dos alunos. Os formulários utilizados em anos anteriores para a seleção de alunos eram impressos, esses formulários eletrônicos de seleção, facilitam uma pré-inserção 
do aluno no mundo digital, eles permitem a realização de filtragem e controle de informação dos alunos como nome completo, idade, série, entre outros. Outro formulário criado foi para a avaliação dos alunos da UFSJ, contendo perguntas relacionadas com a didática, compromisso com o horário, respeito com os alunos, nível de conhecimento, e sugestões de melhorias. A análise das respostas desse formulário é um o objeto importante para a evolução do curso pois o aluno da UFSJ pode fazer uma reflexão do seu modo de lecionar e então tentar melhorar em determinadas questões apontadas para as aulas nas próximas turmas. Por fim, temos o último formulário que é o de seleção de novos voluntários para o projeto, esse formulário é uma forma rápida e de simples compartilhamento para que alunos da UFSJ - Campus Alto Paraopeba possam realizar a inscrição, facilitando assim também o modo de seleção através de determinados requisitos impostos para que alguns sejam selecionados para entrevistas.

Como as apostilas estavam desatualizadas, foi realizado um levantamento de materiais complementares na forma de apostilas e de vídeos, para que o bolsista ou voluntário pudesse ter um conhecimento adequado do assunto, conseguindo explicar da melhor forma possível e com exemplos práticos do dia a dia. Os materiais não se restringiam somente ao conteúdo dado, mas também com recursos avançados que podem ser explorados em atividades extras.

A próxima etapa foi a realização de planilhas eletrônicas. A primeira planilha a ser elaborada foi a de controle de presença dos alunos. Essa planilha contém para cada aba uma turma de alunos onde eram contabilizadas as presenças dos alunos em cada dia de treinamento e no final há um campo demonstrando a porcentagem de presença do aluno e também a quantidade de faltas ao longo dos treinamentos. Esse controle de presença foi muito importante, pois através dele o bolsista pode observar por que determinado aluno não estava mais participando dos treinamentos, e assim comunicando a escola para entender o que havia acontecido, como por exemplo: transferências de escola ou aluno comunicando aos responsáveis que estava indo aos treinamentos, porém na verdade estava se deslocando para outros lugares. Outra planilha elaborada foi a de notas dos alunos que continha todas as notas de avaliações realizadas pelo aluno ao longo dos treinamentos e no fim havia uma função que realizava a soma das notas e exibia o resultado de aprovado ou reprovado para o aluno em questão. 
Os alunos que participavam do projeto eram avaliados através de assiduidade das aulas, provas e trabalho final. As provas e trabalhos eram baseadas nos programas utilizados durante os treinamentos. Os alunos realizavam as provas de LibreOffice Writer, LibreOffice Impress e LibreOffice Calc, e o trabalho final era um jogo desenvolvido no Scratch. As provas eram elaboradas de acordo com a série da turma, diferenciando o nível de dificuldade entre uma turma de $2^{\circ}$ ano do ensino médio e para uma turma do $5^{\circ}$ ano do ensino fundamental, por exemplo. Para o Scratch eram apresentados aos alunos cinco diferentes tipos de jogos que deveriam ser escolhidos para fazer como trabalho final. Ressalta-se que todas as avaliações eram precedidas de simulados para que os alunos pudessem reforçar ainda mais o aprendizado e também para ambientação do estilo de prova a ser aplicado.

Construído então uma base bem estruturada, o projeto pôde se expandir chegando ao ponto de realizar um processo seletivo para atuação de voluntários. Esse processo obteve como resultado em números a inscrição de 7 candidatos, sendo 3 deles aprovados ao final do processo seletivo, e também foi obtido um resultado de despertar o interesse dos alunos da Universidade em conhecer melhor e participar do projeto, realizar essa troca de saberes entre a comunidade e a Universidade. Todos os aprovados têm suas respectivas funções de atuação bem definidas.

Como já foi citado, as apostilas estavam desatualizadas ocasionando assim uma dificuldade dos alunos em acompanhá-las, e também para o bolsista que estava lecionando, ocorrendo em muitas vezes o improviso para que os alunos pudessem compreender as mudanças de comandos, opções e figuras. Com isso, foi realizado uma atualização, onde o aluno possa acompanhar a versão mais recente dos programas. No caso das atualizações das atividades do Scratch, foi desenvolvido através pesquisas de videoaulas e apostilas no site do próprio programa, jogos de lógicas básicas e Scratch Cards (Cartões de programação/jogos), para que a aula ficasse sob maior controle do bolsista.

No final do projeto um relatório completo dos treinamentos era enviado à escola que os alunos participavam, esse relatório continha as datas, e nome das pessoas que participavam das reuniões entre bolsista e escola, descrevendo o que foi decidido em cada encontro, realizando assim toda a forma de contato e decisões de atuações do projeto na escola em si. Além disso, o relatório continha todo o conteúdo ministrado em cada dia de treinamento, fazendo com que o bolsista pudesse ter controle de onde determinada turma parou, e 
também para que a escola pudesse observar que os alunos não estavam realizando o treinamento em vão. Nos campos finais do relatório existe os pontos negativos e positivos de atuação no projeto na escola, lá eram listados pontos como: empenho dos alunos em aprender ou horário não favorecido para os alunos. Com base nisso um campo de sugestões foi inserido para que o bolsista pudesse realizar uma análise por completo do projeto, e então dê sugestões de melhorias a escola, para que a infraestrutura do laboratório, comportamento de alunos, horários, entre outros, sejam revistos para quando houver outros treinamentos, eles tenham melhores condições de realização. Por fim temos uma conclusão de todos os pontos levantados ao longo do relatório.

A execução do projeto de extensão pode ser descrita segundo as seguintes fases:

1. Planejamento: Nesta etapa é feita uma reunião entre os bolsistas, voluntários, coordenador e orientador para que as estratégias do semestre sejam traçadas, definindo questões como quais escolas serão atendidas, faixa etária dos alunos, métodos de seleção. A partir dessa reunião realiza-se uma visita à escola definida para reconhecimento dos equipamentos e do laboratório da escola, onde avalia-se suas condições para que o projeto seja executado. Os itens a serem avaliados são: presença de um quadro escolar para que a visualização dos temas por parte dos alunos seja possível; organização e disposição dos equipamentos para que o bolsista ou voluntário tenha uma visão geral e acesso a todos os computadores, iluminação e ventilação. É realizada também uma verificação dos equipamentos em relação ao funcionamento para a definição de quantos alunos poderão participar do curso. Realiza-se uma reunião com o responsável pela escola para a definição de turmas e também os horários dos treinamentos. É feita uma pesquisa a fim de conhecer o perfil dos alunos e o nível dos conhecimentos dos alunos, para que o projeto seja conduzido da forma adequada. As planilhas de controle de presença, planilhas de notas, relatórios de atividades, exercícios e provas são atualizadas para as novas turmas. Também são desenvolvidos materiais didáticos e atualizações de outros, para que o aluno possa estar diante do que há de mais novo em relação aos programas de computador e feito o calendário de treinamentos. Esta etapa é composta pelas seguintes atividades:

I. Realizar reuniões entre os membros atuantes no projeto; 
II. Realizar contato inicial com a escola;

III. Realizar mapeamento dos laboratórios de informática;

IV. Realização da pesquisa com os alunos quanto ao perfil e nível de conhecimentos;

V. Desenvolver/atualizar o material didático para os alunos;

VI. Desenvolver/atualizar o material de apoio para as aulas;

VII. Definir o calendário de treinamentos, horários, datas e alunos integrantes de cada turma acompanhado da direção de cada escola.

2. Alunos do ensino médio: Nesta etapa pretende-se realizar o treinamento nos alunos do ensino médio, composta pelas atividades:

I. Organização e verificação do laboratório para alunos;

II. Realização do treinamento para alunos;

III. Realização de pesquisa de satisfação com alunos envolvidos;

IV. Emissão e entrega de certificados.

3. Alunos de ensino fundamental: Nesta etapa pretende-se realizar as atividades com os alunos do ensino fundamental, composta pelas atividades:

I. Organização e verificação do laboratório para alunos;

II. Realização do treinamento para alunos;

III. Realização de pesquisa de satisfação com alunos envolvidos;

IV. Emissão e entrega de certificados.

4. Alunos de ensino técnico: Nesta etapa pretende-se realizar as atividades com os alunos do ensino técnico, composta pelas atividades:

I. Organização e verificação do laboratório para alunos;

II. Realização do treinamento para alunos;

III. Realização de pesquisa de satisfação com alunos envolvidos;

IV. Emissão e entrega de certificados.

5. Entrega do relatório do curso à escola: Nesta fase é realizado a entrega de um documento contendo os dias e conteúdo das atividades desenvolvidas com os alunos de cada turma, suas respectivas notas e faltas. Além disso, o documento contém pontos negativos e positivos do comportamento da escola e alunos com relação ao curso, observados pelo bolsista ou voluntário atuante. E por fim uma conclusão do 
projeto em geral, com sugestões de melhorias para uma nova oportunidade de curso.

6. Avaliação dos resultados: Nesta fase é feito a avaliação dos resultados obtidos e a documentação do projeto. Além disso, será avaliada a experiência adquirida assim como possíveis melhorias, para que assim possa ser aplicada a metodologia em outras escolas.

\section{Resultados E Discussões}

Com a introdução das noções básicas de programação de computadores, o uso de programas de edição de textos, apresentações e planilhas como o LibreOffice Writer, LibreOffice Impress e LibreOffice Calc para crianças e jovens, foi possível observar um maior envolvimento e desenvolvimento desses alunos no ambiente escolar. Isso deve-se ao fato de que os programas, as atividades e as provas utilizadas nos treinamentos realizam um reforço escolar com o aluno, atuando com exercícios que complementam os conteúdos trabalhados em salas de aula. A utilização de dispositivos como o mouse faz com que a pessoa sabia controlar a velocidade e precisão do local que deseja ir, ajudando muito os alunos com relação a coordenação motora. O programa LibreOffice Writer auxilia o aluno em questões como: leitura, escrita, interpretação de texto, identificação de erros ortográficos entre outros. O LibreOffice Impress auxilia o aluno em questões como: leitura, escrita, interpretação de texto, identificação de erros ortográficos, criatividade de design entre outros. E por fim o LibreOffice Calc auxilia o aluno em questões como: leitura, escrita, operações matemáticas, raciocínio lógico entre outros.

Com uso do Scratch as crianças obtiveram o contato com a forma de aprender através de desafios de forma divertida e interativa, utilizando blocos lógicos, itens de som e imagem. No Scratch as crianças desenvolvem suas próprias histórias interativas, jogos e animações, além de compartilhar de maneira online suas criações.

Os projetos realizados nos anos anteriores contemplaram o atendimento de mais de 500 alunos com emissão de certificado para todos que concluíram o curso. Houve uma conscientização sobre o uso dos instrumentos computacionais e foi possível auxiliar o ingresso desses alunos no mercado de trabalho onde o domínio de um computador é um requisito fundamental. 
A integração da universidade com a comunidade escolar foi um fator muito positivo, pois facilitou a comunicação entre as partes e trouxe melhorias para as escolas, tornando ativos laboratórios de informática que estavam se tornando obsoletos e sem utilização. Foi possível despertar o interesse dos alunos e disseminar o conhecimento sobre o mundo digital. Através dos cursos realizados nas 8 turmas, 124 alunos receberam treinamento no ano de 2015. No ano de 2017 foram atendidas 3 escolas com formação de 8 turmas totalizando 115 alunos que receberam o treinamento. Atualmente muitos passaram a frequentar os laboratórios sob orientação dos professores das escolas.

Em parceria com a Superintendência Regional de Ensino - SRE, dezesseis escolas públicas estaduais foram contempladas no ano de 2015 pelo projeto onde três bolsistas da UFSJ orientados por dois docentes faziam a manutenção dos laboratórios de informática. A parceria continuou em 2017, onde três escolas públicas estaduais foram contempladas pelo projeto onde um bolsista e um voluntário realizavam os treinamentos nas escolas orientados por dois docentes da UFSJ.

Além do trabalho com a manutenção dos laboratórios, foi ministrado cursos básicos de informática de curta duração na Escola Estadual Domingos Bebiano, beneficiando 124 alunos dos $7^{\circ}$ e $8^{\circ}$ anos do ensino fundamental. Para o ano de 2017 foram ministrados cursos básicos de informática de 24 horas de duração na Escola Estadual Domingos Bebiano beneficiando 7 alunos dos $2^{\circ}$ e $3^{\circ}$ anos do ensino médio, 26 horas de duração na Escola Estadual Professora Maria Augusta Noronha beneficiando 55 alunos do $5^{\circ}$ ano do ensino fundamental e do $1^{\circ}, 2^{\circ}$ e $3^{\circ}$ ano do ensino médio, 33 horas de duração na Escola Estadual Professora Astor Vianna beneficiando 53 alunos do $5^{\circ}$ e $8^{\circ}$ ano do ensino fundamental e do ensino técnico.

Com o projeto foi possível conhecer um pouco sobre a realidade da comunidade da escola e perceber seus valores sociais. Ao mesmo tempo foi possível ter a satisfação de obter resultados para os alunos e para as escolas aproximando a Universidade da comunidade onde está inserida. Os alunos tiveram contatos com os bolsistas, moradores muitas vezes das mesmas comunidades que tem a oportunidade de estudar em uma universidade pública e de qualidade.

Notícias sobre o projeto foram divulgas nos meios de comunicação da cidade de Conselheiro Lafaiete - MG, enfatizando a parceria entre a UFSJ e a Secretaria Municipal de Educação. O projeto beneficiou escolas públicas da cidade, sem custos para o município, e enriqueceu o currículo de alunos e bolsistas. 
No ano de 2011 foi apresentado em um congresso sediado na cidade de Porto alegre, capital do Rio Grande do Sul, resultados de projetos de extensão relacionado a inclusão digital nas escolas da região. A participação dos bolsistas alunos da UFSJ neste congresso propiciou uma rica troca de experiências com apresentação de propostas, resultados e tendo a oportunidade de refletir criticamente sobre a extensão universitária no Brasil.

Além de auxiliar o aprendizado dos alunos do ensino básico, o projeto também está conseguindo inserir os alunos em outros projetos da universidade. Recentemente uma aluna da Escola Estadual Professora Maria Augusta Noronha do $2^{\circ}$ ano do ensino médio, foi indicada a uma bolsa no PROGRAMA DE BOLSAS INSTITUCIONAIS DE INICIAÇÃO CIENTÍFICA JÚNIOR DA FAPEMIG - (BIC-JÚNIOR). O BIC-JÚNIOR tem como objetivo contribuir para a iniciação de estudantes do ensino fundamental, médio e de educação profissional da Rede Pública, permitindo-os participarem de atividades de pesquisa e de extensão científica ou tecnológica. Estes alunos são orientados por pesquisadores qualificados através da concessão de cotas de bolsas de Iniciação Científica Júnior. ${ }^{[7]}$ Os alunos são selecionados baseados na assiduidade nos treinamentos e por ter obtido boas notas nas avaliações. Esse foi um ótimo exemplo para a comunidade pois demonstra que o comprometimento com as atividades escolares permite que oportunidades sejam abertas e que todos são capazes de conseguir.

Como em todo projeto dessa natureza, os números são extremamente importantes, sejam para demonstrar a quantidade de escolas e alunos atendidos, gerar gráficos de diversas informações ou prever resultados futuros. Porém, buscando a real essência de um projeto de extensão de uma universidade, o melhor resultado que podemos obter é o carinho, a alegria, o reconhecimento e a satisfação dos alunos que participaram do projeto. Um projeto também não ensina somente conhecimentos básicos em informática, mas também o respeito ao próximo e demonstra um caminho para aqueles que muitas vezes têm tão pouco e não tem ninguém que estenda a mão. As Figuras apresentadas abaixo neste trabalho, demonstram os alunos do $5^{\circ}$ ano do ensino fundamental da Escola Estadual Professora Maria Augusta Noronha no último dia de treinamento, e observando as mesmas nos fazem sentir que o objetivo foi cumprido e nos auxilia a continuar o trabalho mesmo com algumas dificuldades inerentes as relações humanas. 
Ficura 2: Cartaz realizado pelos alunos

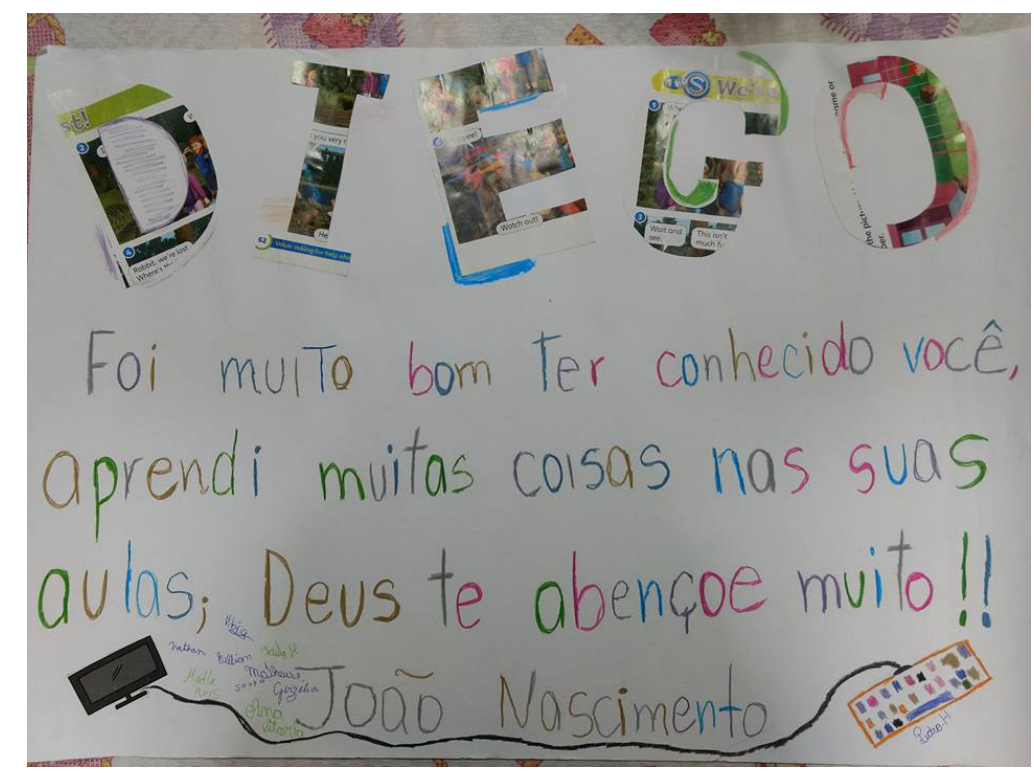

\section{Conclusão}

Após os resultados obtidos observamos que foi possível ativar os laboratórios de informáticas das escolas contempladas pelo programa. A disponibilidade dos laboratórios passou a ser garantida e com isso alguns professores sentiram-se mais confiantes e passaram a levar os alunos para o laboratório. Além disso, foi possível despertar o interesse dos alunos e disseminar o conhecimento sobre o mundo digital, entender sobre a realidade da comunidade escolar, percebendo assim, seus valores sociais. Ao mesmo tempo, ter a satisfação de obter resultados para os alunos e para as escolas, aproximando a Universidade da comunidade onde está inserida.

Para 2018 pretende-se ampliar os cursos de capacitação, seja na forma de maior número de escolas e turmas possíveis, ou inserindo mais conteúdo que contribuam para o engrandecer do aluno. Pretende-se estender as ações para os professores, funcionários e familiares dos alunos, com um aumento da qualidade dos cursos devido aos métodos adotados e apostilas oferecidas. Em virtude do que foi observado nos projetos anteriores conclui-se que os alunos e professores serão agraciados com a extensão do projeto, que será bem organizado e elaborado em 2018 para dar continuidade aos ótimos resultados obtidos anteriormente. 


\section{REFERÊNCIAS}

[1] Portal Governo Eletrônico: Disponível em: <https://www.governoeletronico. gov.br/Plone/eixos-de-atuacao/cidadao/inclusao-digital/programa-de-inclusao-social-e-digital> de acesso: 15/02/2018.

[2] Instituto Brasileiro de Geografia e Estatística. Disponível em: $<$ https://cidades. ibge.gov.br/brasil/mg/conselheiro-lafaiete/panorama> data de acesso: 15/02/2018.

[3] Mapa da Inclusão Digital. Disponível em: $<$ http://www.cps.fgv.br/cps/telefonica/> data de acesso: 15/02/2018.

[4] <http://www.cbeu.eventsystem.com.br/gerar_pdf.php?id=3484> data de acesso: 18/02/2018.

[5] Scratch Brasil. Disponível em: $<$ http://www.scratchbrasil.net.br/ $>$ data de acesso: $15 / 02 / 2018$.

[6] OLIVEIRA, et al. Roteiro para criação de Unidades de Conservação Municipais. Brasília, MMA, 2010.

[7] <https://www.google.com/url? sa =t\&rct=j\&q=\&esrc=s\&source=web\&cd=2\& cad=rja\&uact $=8 \& v e d=0$ ahUKEwjEz63ywq7ZAhWFgJAKHfx0AkoQFggxMAE\&url =https\%3A\%2F\%2Fufsj.edu.br\%2Fportal-repositorio\%2FFile\%2Fprope\%2FArquiv os_site_PROPE\%2Fnormaspibicjunior.doc\&usg=AOvVaw0JwkRn7CqOF98mXuln2 pSD> data de acesso: 18/02/2018. 